\title{
Relato de uma experiência de estágio supervisionado em ciências desenvolvida a partir da perspectiva da educação para a sexualidade
}

\section{Report on the experience of a supervised internship in sciences developed through the perspective of education to sexuality}

\author{
Ronan Moura Franco (rmourafranco@gmail.com) \\ Universidade Federal do Pampa (UNIPAMPA), Campus Uruguaiana \\ Julio Cesar Bresolin Marinho (marinhojcb@gmail.com) \\ Universidade Federal do Pampa (UNIPAMPA), Campus São Gabriel \\ Fabiane Ferreira da Silva (fabianesilva@ unipampa.edu.br) \\ Universidade Federal do Pampa (UNIPAMPA), Campus Uruguaiana
}

\section{Resumo:}

Este trabalho tem por objetivo relatar e refletir experiências vivenciadas no processo de desenvolvimento da componente curricular Estágio Supervisionado II do curso de Ciências da Natureza - licenciatura, da Universidade Federal do Pampa, campus Uruguaiana/RS. Para tanto, foram planejadas, desenvolvidas e avaliadas 17 aulas em uma perspectiva da educação para a sexualidade, organizadas em uma Unidade de Aprendizagem que tinha como temática central o estudo do sistema genital na disciplina de Ciências nos Anos Finais do Ensino Fundamental e registradas em diários reflexivos. O desenvolvimento do Estágio Supervisionado II na perspectiva da educação para a sexualidade possibilitou uma ampliação dos entendimentos referentes ao tema, desconstruindo discursos e práticas naturalizadas pela sociedade. Consideramos importante a inserção de temas como corpo, gênero e sexualidade nos currículos dos cursos de licenciatura, a fim de formar profissionais preparados/as para trabalhar na perspectiva da diversidade e da garantia dos direitos humanos.

Palavras-chave: Sexualidade; Sistema genital; Unidades de Aprendizagem; Estágio Supervisionado; Formação docente.

\begin{abstract}
:
This thesis aims to report and reflect on the experiences lived through the process of development from the curricular component Supervised Internship II of the Natural Sciences course - graduation, from 'Universidade Federal do Pampa', Uruguaiana/RS campus. For that, were planned, developed and evaluated 17 classes in the perspective of education to sexuality, organized in a Learning Unity that had as a central theme, the study of the genital system in the Science subject, at the Final Years of elementary school, and recorded in reflective entries. The development of the Supervised Internship
\end{abstract}


II at the perspective of education to sexuality, made a growth in the subject understanding possible, deconstructing speeches and practices already naturalized by society. We consider to be important, the insertion of themes, such as body, gender and sexuality, at the graduation courses resumes, training capable professionals, ready to work from a diversity point of view, in order to guarantee human rights.

Keywords: Sexuality; Genital System; Learning Unity; Supervised Internship; Teacher Training.

\section{INTRODUÇÃO}

A problemática da educação escolar está na pauta diária e engloba diferentes aspectos: universalização da escolarização, qualidade da educação, projetos políticospedagógicos, concepções de currículo, relações com a comunidade, papel social da escola, indisciplina e violência, avaliação, formação de professores/as, dentre outros aspectos (CANDAU, 2013). Nesse contexto, emerge a necessidade de um ensino voltado para a formação da cidadania, uma vez que os processos de desenvolvimento da sociedade, se ampliam, exigindo que as mudanças na educação contemplem tais exigências (BRASIL, 1997). Conforme argumentam Hames e Kemp (2019, p. 68) "não se pode pensar uma formação para a cidadania, nos moldes em que prevê a legislação educacional brasileira, desconsiderando a abordagem das questões de gênero e diversidade sexual." Cabe lembrar que o trabalho docente não se caracteriza como uma atividade neutra, sendo revestido de atributos ideológicos, em que toda ação pedagógica infere em uma postura política (FREIRE, 1996). Na busca da formação para a cidadania e assumindo o compromisso político-social da docência é que se desenvolve este trabalho, que tem como objetivos relatar e refletir experiências vivenciadas no processo de desenvolvimento da componente curricular Estágio Supervisionado II do curso de Ciências da Natureza ${ }^{1}$ - Licenciatura, da Universidade Federal do Pampa, campus Uruguaiana/RS.

O Estágio Supervisionado possibilita a inserção dos/as licenciandos/as no contexto profissional, atuando na educação básica, em situações referentes ao processo de ensino-aprendizagem na área de ciências naturais no Ensino Fundamental. A realização do referido estágio alinha-se a Lei $\mathrm{n}^{\circ} 11.788$, que dispõe sobre o estágio de estudantes, definindo essa atividade como um ato educativo escolar supervisionado, desenvolvido no ambiente de trabalho, visando à preparação para o trabalho produtivo de educandos que estejam frequentando o ensino regular em instituições de educação superior (BRASIL, 2008).

Os estágios nas licenciaturas podem ser entendidos enquanto um momento em que se reflete e propõe estratégias de ensino que possibilitam a formação daquele/a que estagia. Uma das finalidades do estágio é a de propiciar ao aluno uma vivência da realidade, onde exercerá sua função docente, ainda aproxima as relações entre

${ }^{1}$ O curso de Ciência da Natureza - Licenciatura tem por objetivo a formação de professores para o exercício docente na área de ciências da natureza e suas tecnologias no ensino médio (foco de conhecimento específico em química, física e biologia) e ciências naturais no ensino fundamental (UNIPAMPA, 2013, p. 28). 
universidade e escola. A relação entre as universidades e as escolas não pode se caracterizar como cobrança ou fiscalização das ações educativas, mas uma ação cooperativa, visando à melhoria do ensino (KRASILCHIK, 2008). Esta ligação deve proporcionar aos estagiários uma reflexão sobre a realidade da escola e assim, contribuir com a construção de novas perspectivas, a partir de práticas pedagógicas formativas.

Segundo Pimenta e Lima (2004), o estágio pode ser compreendido como um espaço de reflexão sobre a construção da identidade do educador em formação e deve ser entendido como eixo central nos cursos de formação de professores/as. As autoras afirmam que o estágio deve ser compreendido com um trabalho colaborativo, pois neste espaço, será desenvolvido um trabalho em que serão percebidos os distanciamentos e proximidades entre a teoria e a prática. "O desafio é proceder como um intercâmbio, durante o processo formativo, entre o que se teoriza e o que se pratica" (PIMENTA; LIMA, 2004, p. 127). Nessa perspectiva de articulação, aproximando teoria e prática, é que se desenvolveram as atividades de estágio que serão relatadas neste texto.

As componentes curriculares de Estágio Supervisionados previstas no Projeto Pedagógico do Curso (PPC) de Ciências da Natureza - Licenciatura, objetivam oportunizar tempo e espaços formais de atuação em sala de aula, a fim de vivenciar práticas docentes de forma contextualizada, articulando conhecimentos teóricos e práticos desenvolvidos durante o curso de licenciatura, na perspectiva de problematizar o contexto escolar e a formação docente (UNIPAMPA, 2013). De acordo com o PPC do curso de Ciências da Natureza, os estágios totalizaram 420 (quatrocentos e vinte) horas de carga horária, divididas da seguinte forma: 90 (noventa) horas para o Estágio Supervisionado I que ocorre no $7^{\circ}$ semestre do curso, realizado no Ensino Fundamental; 150 (cento e cinquenta) horas para o Estágio Supervisionado II, no $8^{\circ}$ semestre, com regência de classe no Ensino Fundamental, e 180 (cento e oitenta) horas para o Estágio Supervisionado III, que ocorre no $9^{\circ}$ semestre do curso, com regência de classe no Ensino Médio (UNIPAMPA, 2013).

O Estágio Supervisionado I compreende as atividades de observação de aulas, da escola e seu entorno com relato reflexivo, bem como o planejamento das atividades a serem executadas pelo/a estagiário/a no Estágio Supervisionado II no contexto do Ensino Fundamental. Ainda durante o Estágio Supervisionado I o/a acadêmico/a realiza atividades na universidade, tais como: leituras e fichamentos de textos, apresentações de seminários, elaboração de uma Unidade de Aprendizagem contendo o planejamento das atividades e discussão no coletivo das experiências do estágio. Já o Estágio Supervisionado II, foco do presente artigo, compreende a regência de classe na disciplina de ciências, nos anos finais do Ensino Fundamental, na qual se desenvolve a Unidade de Aprendizagem elaborada no Estágio Supervisionado I.

Esta escrita foi construída em quatro partes que se complementam. Para além dessa parte introdutória que contextualizou os estágios em diferentes níveis, na sequência serão apresentados alguns pressupostos teóricos que fundamentaram o planejamento, a execução e a avaliação do estágio. Logo após, são revisitadas algumas aulas que consideramos pertinentes de serem ilustradas por reflexões teorizadas do diário do estagiário e finalizamos este relato com as (in)conclusões, onde argumentamos 
sobre a importância da abordagem das questões de corpo, gênero e sexualidade para a educação básica e a formação de professores/as.

\title{
2. UNIDADES DE APRENDIZAGEM COMO PROPOSTA DIDÁTICA DE "EDUCAÇÃO PARA A SEXUALIDADE"
}

Para o planejamento das aulas foi proposto a construção de uma Unidade de Aprendizagem na perspectiva do referencial teórico proposto por Galiazzi, Garcia e Lindemann (2004). A proposição das Unidades de Aprendizagem busca superar a fragmentação e o planejamento sequencial que é apresentado nos livros didáticos e a forma tradicional com que a sala de aula geralmente é pensada. As autoras afirmam que:

\begin{abstract}
Com certeza podemos criticar nossa falta de criatividade, como professores, ao não alterar a sequiência de conteúdos assumida pelo autor do livro didático. Talvez porque, acostumados a repetir uma história em aula contada por nossos mestres, seguimos apresentando os conteúdos na mesma ordem em que a nós foi proposta por eles, que também seguiam a seqüência inquestionada. (GALIAZZI; GARCIA; LINDEMANN, 2004, p. 67).
\end{abstract}

Nesse sentido, as Unidades de Aprendizagem podem ser consideradas maneiras alternativas de planejamento, elaboração e organização dos trabalhos em sala de aula.

\begin{abstract}
Uma unidade de aprendizagem, embora tenha início, meio e fim, também é uma construção que na recursividade agrega complexidade na sua estrutura sempre flexível e em questionamento. A cada aula, ou mesmo a cada diálogo, se reestrutura, se amplia, se reduz, se transforma (GALIAZZI; GARCIA; LINDEMANN, 2004, p. 100).
\end{abstract}

Dessa forma, ao ser construída uma Unidade de Aprendizagem deve-se considerar e valorizar o conhecimento que o/a aluno/a traz, as informações da mídia, as crenças, ideologias, pois se entende que o objetivo da escola é enriquecer o conhecimento do/a aluno/a, favorecendo aprendizagens que o capacitem a tomar decisões responsáveis (GALIAZZI; GARCIA; LINDEMANN, 2004). Ressalta-se que o planejamento de Unidades de Aprendizagem engloba vários momentos, desde a escolha do tema até a avaliação da própria unidade, bem como inclui o permanente questionamento sobre a coerência das relações entre as partes que a constituem.

No contexto dos estágios supervisionados no curso de Ciências da Natureza uma das propostas é que os/as estagiários/as construam diários de aula reflexivos sobre suas experiências, de modo a contribuir com a formação profissional e a qualificação da prática pedagógica. Para Doleski e Silva (2019, p. 201) "o diário de aula pode ser concebido então como algo que vai além de uma escrita meramente descritiva, exigindo do/a professor/a uma narrativa reflexiva que contemple os aspectos mais marcantes de sua prática".

Zabalza (2004) afirma que os diários de aula, tornaram-se ferramentas importantes, pois neles ocorre a exposição, explicação, interpretação da ação diária na aula ou fora dela. Ainda, Zabalza afirma que

o próprio fato de escrever, de escrever sobre a própria prática, leva o professor a aprender por sua narração. Ao narrar sua experiência recente não 
só constrói linguisticamente como a reconstrói como discurso prático e como atividade profissional (2004, p. 44).

Desse modo, os registros em diários de aula tornam-se uma ferramenta fundamental de formação, pois este é um instrumento dinamizador e crítico entre teoria e prática, bem como potencializador da reconstrução da identidade profissional docente.

A Unidade de Aprendizagem foi elaborada de modo a abordar o sistema genital masculino e feminino - conteúdo disponibilizado pela regente da turma de estágio - na perspectiva da "educação para a sexualidade".

Desse modo, para integrar os conteúdos desenvolvidos na Unidade de Aprendizagem, apostou-se na perspectiva da "educação para a sexualidade" segundo Xavier Filha (2009). Nesta condição, compreende-se a educação para sexualidade como uma possibilidade diferenciada de abordagem que possibilita problematizar e desconstruir modelos hegemônicos que constituem a educação e a sexualidade. A educação para a sexualidade compreende ampliar o entendimento de que existe uma multiplicidade de formas da sexualidade para ser trabalhada, como afirma a autora:

A perspectiva da educação para a sexualidade pretende refletir sobre discursos naturalizados e sacralizados culturalmente, relativizando-os, pondoos sob suspeita e vigilância, provocando a dúvida de algumas certezas, permitindo-se novas formas de pensar e com isso estimular questionamentos sobre como nos constituímos em relações de saber e poder. Com isso, desestabilizar certezas, na tentativa de ampliar olhares em outras direções e possibilidades (XAVIER FILHA, 2009, p. 97).

O trabalho pedagógico na perspectiva da educação para a sexualidade se distancia de determinadas formas de nominar e abordar a educação em relação à sexualidade. Os termos Educação Sexual e Orientação Sexual, apesar de amplamente utilizados, remetem-se à práticas estritamente biológicas, moralistas, higienistas e que desconsideram os sujeitos sexuados inseridos em determinados contextos sociais (XAVIER FILHA, 2009). Quando se trabalha com educação e sexualidade é importante pensarmos qual a terminologia que será adotada para nominar essa proposta, pois estas, são construções sócio-histórico-culturais, estando dessa forma, sob tensão permanente, sofrendo alterações, fixando determinados significados e excluindo outros. Educar para sexualidade é mais um significado mutável e transitório, mas que possibilita uma discussão das maneiras de pensar as práticas educativas.

Abordar a sexualidade na escola não é tarefa fácil, já que para algumas pessoas, a sexualidade é entendida como uma questão biológica, pessoal e íntima, e a escola, entendida como uma instituição formal é responsável pelo ensino de determinados conteúdos (LOURO, 2000; SILVA, 2011). Assim, não cabe a escola falar sobre sexualidade, mas à família. Contudo, em oposição a esse entendimento, argumentamos que é impossível separar a sexualidade da escola, pois conforme Louro (2000, p. 86), a sexualidade "é mais do que uma questão pessoal e privada, ela se constitui num campo político, discutido e disputado." Conforme argumenta Silva (2011, p. 144) a sexualidade é uma "construção social, histórica e cultural, produto e efeito das relações de poder/saber. Não é universal. Não é algo inerente ao ser humano. Não é uma essência do sujeito que se manifesta em determinado momento da vida. Portanto, não é biologicamente determinada." A sexualidade inscreve linguagens, comportamentos, 
desejos, crenças, valores, escolhas, identidades, posturas no corpo, através de algumas estratégias de poder/saber sobre os sexos (RIBEIRO, 2002).

Nessa perspectiva, a sexualidade tem muito mais a ver com a cultura e a história do que com a própria biologia, lembrando que a biologia tem uma história que não é natural, também se trata de uma construção. A sexualidade envolve os modos como as pessoas, social e historicamente, vivem seus desejos e prazeres; às formas pelas quais os sujeitos são incitados a falar sobre ela; às formas pelas quais o sujeito é disciplinado e a sociedade é governada.

\section{REVISITANDO O ESTÁGIO SUPERVISIONADO II: (RE)SIGNIFICANDO EXPERIÊNCIAS}

O Estágio Supervisionado II foi realizado numa escola municipal de Ensino Fundamental de Uruguaiana. No período de realização do estágio, a referida escola atendia cerca de 650 alunos/as do $1^{\circ}$ ao $9^{\circ}$ ano do Ensino Fundamental de várias localidades e bairros do município. A turma escolhida para o desenvolvimento das atividades foi uma turma de $8^{\circ}$ ano que contava com 16 alunos/as, sendo 10 alunos e 06 alunas. As atividades foram realizadas na disciplina de Ciências que dispunha de três horas/aula semanais, totalizando 26 horas de atividade de regência de classe. Essas atividades foram organizadas em aulas, conforme apresentamos no quadro abaixo:

Quadro 1 - Aulas da Unidade de Aprendizagem

\begin{tabular}{|c|c|}
\hline Aula e Temática & Objetivo \\
\hline $\begin{array}{l}1 \text { - Apresentação da proposta de } \\
\text { estágio. }\end{array}$ & $\begin{array}{c}\text { Compreender a proposta de estágio, métodos das aulas e } \\
\text { avaliações }\end{array}$ \\
\hline $\begin{array}{l}2 \text { - "Como eu me vejo, como os outros } \\
\text { me veem". }\end{array}$ & $\begin{array}{l}\text { Refletir sobre o olhar que cada sujeito tem sobre si, a partir do } \\
\text { olhar do outro }\end{array}$ \\
\hline $\begin{array}{c}\text { 3- Representações sobre corpo, gênero } \\
\text { e sexualidades }\end{array}$ & $\begin{array}{c}\text { Contribuir para a criação de um espaço de reflexão e discussão } \\
\text { dos temas de corpo, gênero e sexualidades }\end{array}$ \\
\hline $\begin{array}{l}4-\text { Representações de feminino e } \\
\text { masculino em Artefatos Culturais }\end{array}$ & $\begin{array}{l}\text { Compreender as múltiplas representações de masculinidades e } \\
\text { feminilidades em artefatos culturais (livros, revistas e encartes) }\end{array}$ \\
\hline 5 e 6 - Hormônios Sexuais & $\begin{array}{l}\text { Entender as mudanças corporais e sexuais provocadas pelos } \\
\text { diferentes hormônios e suas implicações sociais e culturais }\end{array}$ \\
\hline $7,8,9$ e $10-$ Sistemas Genitais & $\begin{array}{l}\text { Compreender as anatomias e fisiologias dos sistemas genitais } \\
\text { em uma perspectiva biológica, cultural, social e histórica }\end{array}$ \\
\hline 11 e 12 - Sexualidades & $\begin{array}{l}\text { Construir conhecimentos acerca das múltiplas possibilidades } \\
\text { de expressão das sexualidades }\end{array}$ \\
\hline 13 - Avaliação Conceitual & $\begin{array}{l}\text { Realizar uma avaliação conceitual sobre as temáticas } \\
\text { trabalhadas }\end{array}$ \\
\hline $\begin{array}{l}14 \text { e } 15 \text { - Infecções Sexualmente } \\
\text { Transmissíveis (IST) }\end{array}$ & $\begin{array}{l}\text { Compreender e apresentar as diferentes IST na forma de } \\
\text { seminários }\end{array}$ \\
\hline 16 - "Fala sério ou com certeza" & $\begin{array}{l}\text { Problematizar dúvidas e mitos sobre os diferentes temas } \\
\text { abordados em aula }\end{array}$ \\
\hline $\begin{array}{l}\text { 17- Encerramento e Avaliação das } \\
\text { Aulas }\end{array}$ & $\begin{array}{l}\text { Avaliar o desenvolvimento das aulas do estágio, bem como a } \\
\text { atuação do estagiário }\end{array}$ \\
\hline
\end{tabular}


Para a construção desta seção, serão apresentadas dezesseis situações vivenciadas durante o desenvolvimento do Estágio Supervisionado II, que se considera pertinente à discussão apresentada neste trabalho.

Cabe destacar que o curso de Ciências da Natureza do campus Uruguaiana possui um componente curricular específico para trabalhar esses temas, que é o componente curricular "Corpo, gênero, sexualidade e relações étnico-raciais na educação" que busca discutir as questões de corpo, gênero, sexualidade, etnia e raça como produções

\section{históricas culturais e sociais, bem como, as implicações das práticas sociais e de diferentes artefatos culturais na constituição dos sujeitos, o sexismo e homofobia no contexto escolar e em outras instâncias sociais, a violência sexual e de gênero e equidade no contexto atual (UNIPAMPA, 2013, p. 28).}

Nesse sentido, a proposta de estágio contou com o suporte teórico da componente curricular "Corpo, gênero, sexualidade e relações étnico-raciais na educação" oferecida no $6^{\circ}$ semestre do curso de Ciências da Natureza.

Inicialmente a proposta de estágio foi apresentada para a turma no primeiro encontro com o acadêmico-estagiário, enquanto regente de classe. Para a dinâmica inicial de apresentação a turma organizou-se em uma roda de conversa, essa organização da aula foi adotada em diferentes momentos durante o decorrer do estágio, possibilitando um diálogo coletivo. Cabe destacar que alguns/as alunos/as contestaram as formas de avaliação, argumentando que a professora titular não realizava avaliação conceitual. Para ilustrar esse primeiro dia de aula destacamos a narrativa a seguir:

Após todos/as se apresentarem, o que aconteceu de maneira tranquila, retomei algumas regras da escola a serem seguidas e que o respeito e diálogo norteariam a realização do trabalho, que a qualquer momento aqueles/as que não estivessem de acordo com alguma situação que ficassem à vontade para expressar suas opiniões, todos/as estavam de acordo. Posteriormente, foram expostas as formas de avaliação dividas em 3 partes: avaliação conceitual, seminário sobre as IST e participação e envolvimento na realização das atividades, sendo esta última, diária e permanente. As datas e valores das avaliações foram negociadas, pois foi exposto pela turma que a professora não realizava avaliação conceitual (provas), dessa forma a porcentagem de nota referente a esta avaliação foi diminuída, e compensada nas outras atividades. Essa atitude de negociar com a turma se mostrou significativa, pois estava estabelecendo-se uma relação política de flexibilidade e diálogo, respeitando ambas as partes. (Diário do estagiário - Aula 1).

O trecho da primeira aula evidencia a importância do diálogo a fim de estabelecer os acordos para o desenvolvimento das atividades como: os objetivos das aulas, os instrumentos avaliativos, responsabilidade na entrega de trabalhos, assiduidade e pontualidade, dentre outros aspectos. Este acordo foi proposto e discutido nessa aula, pois são nesses momentos de início das atividades que o professor estabelece $o$ compromisso mútuo do trabalho pedagógico, construindo a intencionalidade com que as aulas foram planejadas e desenvolvidas. Esse conjunto de acordos é definido como "contrato didático" (PINTO, 2003), caracterizado pelas convenções de regras e procedimentos estabelecidos através de negociações democráticas, propostas pelo/a professor/a e, problematizadas coletivamente. Pinto (2003) ao discutir sobre a dinâmica de construção do contrato didático, afirma que "é, pelas regras do jogo estabelecidas pelo contrato didático, pelas situações que lhes são propostas na relação didática, que o aluno concretiza a passagem da dependência à autonomia" (PINTO, 2003, p. 09). 
Entendemos então, que o contrato didático quando assumido como uma forma dialógica de interação entre os sujeitos que integram o processo de ensinoaprendizagem se configura como oportunidade formativa dos/das alunos/alunas aprenderem a negociar e cooperar, construindo sua autonomia e protagonismo frente às tomadas de decisões em relação a saberes que anteveem o conteúdo conceitual. Apesar das posições diferentes assumidas em sala de aula, a práxis do contrato didático como processo contínuo e recursivo, pode contribuir para a construção de um espaço favorável de efetivação da unidade dialética ensinar-aprender. Dessa forma, o contrato didático deve integrar o processo de ensino aprendizagem, porém destacamos a abordagem inicial do processo investigado, por ser o primeiro contato do acadêmicoestagiário enquanto regente de classe.

$\mathrm{Na}$ aula seguinte, realizou-se a atividade intitulada "Como eu me vejo, como os outros me veem", com objetivo de refletir sobre o olhar que cada sujeito tem sobre si, a partir do olhar do outro. Essa atividade iniciou com os/as alunos/as organizando-se em círculo. Cada aluno/a escreveu o seu nome em uma folha em branco. A folha com o nome de cada aluno/a foi entregue ao colega sentado à sua direita, que escreveu uma palavra relacionada às suas características físicas e/ou pessoais, passando ao próximo colega, obedecendo a um sentido que possibilitasse a participação de toda a turma. Ao retornar ao titular, a folha continha muitas características atribuídas para aquela pessoa, que deveria socializar com os/as demais colegas o que havia sido escrito. Esta atividade permitiu a exposição de múltiplas características, demonstrando a diversidade de sujeitos que compõem a turma, o que possibilitou relacionar com a sociedade atual. No contexto em que este trabalho foi realizado, se considerou a diversidade, enquanto a multiplicidade de ideias, linguagens, religiões, costumes, comportamentos, valores, classes sociais, nacionalidades, culturas, crenças, raça/etnias, gêneros e sexualidades que constituem os sujeitos. Para ilustrar, apresentamos um recorte do diário reflexivo dessa aula:

Nessa atividade, os/as alunos/as escreveram seus pensamentos e opiniões em relação às/aos colegas, bem como sua aparência. Outros pontos que emergiram nas discussões, foram a cor de pele, o cabelo que era "bom" e "ruim". É importante que eles/as aprendam a necessidade de discutir certas temáticas, inclusive essas, para que percebam o quanto a opinião do/a outro/a pode ser ofensiva à vida de alguém. Será que $\mathrm{meu} / \mathrm{minh}$ colega gosta de ser chamado assim? Assim, com essa atividade, vários assuntos podem ser abordados e levam a conhecimentos que antes eram desconhecidos pelos/as alunos/as, expondo muitas características que aproximam as pessoas, pois muito sobre alguém pode ser "revelado". (Diário do estagiário - Aula 2).

Procurando iniciar as atividades referentes ao estudo do corpo humano, para introduzir o sistema genital, este encontro iniciou com uma roda de conversa e um questionamento central: $\mathrm{O}$ que é o corpo? Muitas respostas emergiram deste questionamento, porém, quase que a totalidade destas, estavam atreladas ao corpo biológico, constituído de maneira fragmentada (cabeça, corpo e membros), sendo reduzido às características anatômicas. Essa aula possibilitou conhecer as concepções da turma acerca do corpo, bem como discutir o corpo para além do aspecto biológico, conforme podemos perceber no trecho do diário abaixo: 
Esse questionamento inicial possibilitou a percepção dos entendimentos da turma e a desconstrução destes discursos, quando discutido que o corpo não é compreendido enquanto apenas biológico, que tem uma história, que se adapta aos diferentes contextos, podendo ser mudado conforme o seu entorno. Muitos/as se surpreenderam quando esse entendimento foi exposto, pois amplia a compreensão até mesmo de quem somos. Os questionamentos seguiram conforme as situações eram expostas como: o que adorna os corpos? O que pode ser mudado nos corpos? Existe somente um sexo, um gênero para os corpos? Isso provocou muito questionamentos, se percebendo o discurso preconceituoso sobre as diferenças e diversidade da sociedade atual. (Diário do estagiário - Aula 3).

Vale lembrar que o discurso legítimo para a abordagem do corpo na escola é o discurso biológico. Conforme argumenta Quadrado,

\begin{abstract}
De modo geral, o corpo do currículo escolar é estático, assexuado, anônimo, sem pés e mãos, dividido em partes, ahistórico, atemporal, sem etnia, deslocado do ambiente, geralmente reduzido a características anatômicas, fisiológicas e genéticas, contribuindo, assim, para a construção de representações centradas no discurso biológico. Esse corpo é apresentado como universal, sendo dotado de um padrão que se repete independentemente de classe, raça, etnia, credo ou geração. Raramente é trabalhado como um sistema integrado, mas nos moldes cartesianos, ou seja, fragmentado, dividido em partes, para que através do estudo de cada um dos seus elementos possa-se (re)construir o todo. (2012, p. 10-11)
\end{abstract}

Entretanto, a partir dos entendimentos de corpo dos/as estudantes buscou-se problematizar o corpo como uma produção híbrida, biológica, histórica e cultural, que está constantemente em transformação, sendo modificado e (re)significado em função das diversas formas com que ele tem sido pensado, narrado, interpretado e vivido, ao longo do tempo, pelas diferentes culturas (QUADRADO, 2008).

Essa perspectiva de compreender o corpo implica em romper com a visão naturalista e essencialista com que o corpo tem sido narrado e pensado ao longo dos tempos, na direção de compreender o corpo como um artefato cultural e histórico, constituído na e pela linguagem.

Em um segundo momento, mas ainda desenvolvendo a atividade sobre a temática de corpo, foram distribuídas revistas e livros para que os/as alunos/as representassem corpos a partir de recortes de imagens. Nos cartazes emergiram corpos brancos, magros, sendo os corpos femininos vinculados a produtos de beleza e maquiagem e os masculinos à academia e jogadores de futebol. A partir destas representações pôde-se desconstruir determinados significados ligados aos corpos para além da perspectiva biológica, problematizando questões de gênero. Argumentou-se sobre as formas pelas quais somos diariamente interpelados pelas práticas de modificação dos corpos, principalmente pela mídia. Ilustradas pelas narrativas que seguem:

Seguindo a aula anterior, nesse encontro foram distribuídas revistas e livros antigos, para que recortassem imagens que representassem adornos, enfeites de diferentes corpos, o que poderiam modifica-los. Muitas imagens foram escolhidas, sendo que as figuras masculinas remetiam a jogadores de futebol, carros, corpos brancos e sarados. Da mesma forma os corpos femininos foram atrelados a produtos de beleza, maquiagem, representados por corpos magros, brancos e com o cabelo liso. Essas imagens foram um excelente conteúdo para se discutir inúmeras temáticas, dentre as realizadas nesta aula destaco: a influência da mídia, o preconceito com os diferentes corpos, raças, etnias e identidades sexuais e de gênero. $O$ diálogo realizado demonstrou-se substancial, em que diversas opiniões foram expostas, 
podendo construir argumentos que contribuam para um olhar diferenciado, questionando verdades e superando preconceitos. (Diário do estagiário - Aula 4).

Quadrado (2008) e Silva (2008) afirmam que são inúmeros os elementos que modificam os corpos como: aparatos eletrônicos, roupas, cosméticos, academia, cirurgias plásticas, tatuagens dentre outros. Assim, os corpos são as sedes dos processos identitários, locais de inscrição das identidades, onde elas adquirem visibilidade: ao olhar para um corpo, supõe-se poder "ler" a identidade do indivíduo, a partir dos símbolos e das marcas que ele representa e carrega (QUADRADO, 2008).

Nas aulas posteriores, em que foram trabalhados os conceitos de hormônios sexuais, emergiu o questionamento das transformações que estas substâncias causam no organismo, precisamente em relação aos/às transgêneros (travestis e transexuais), que fazem uso de hormônios para alterarem suas características físicas biológicas as quais não condizem com a identidade de gênero construída. Conforme mostram as reflexões seguintes:

Iniciei a aula procurando saber quais eram os conteúdos que haviam sido trabalhados anteriormente ao início das atividades de estágio com a professora titular de ciências. Dessa forma, solicitei que todos/as se reportassem ao estudo do sistema endócrino, apontando o que ficou de significativo deste estudo. Retomar esse conteúdo possibilitou estabelecer uma relação com o que havia sido estudado anteriormente e o conteúdo que seria iniciado, no caso o sistema genital. Esta ponte entre o estudo do sistema endócrino e o sistema genital foi propositalmente provocada, pois o conteúdo dos hormônios sexuais e glandular permearia todo desenvolvimento do conteúdo de sistema genital, relacionando e integrando as partes que constituem o organismo humano. (Diário do estagiário - Aula 5).

Para esta aula esperava terminar o conteúdo dos hormônios e iniciar o conteúdo do sistema genital, porém durante o diálogo, emergiu o questionamento a partir dos/as alunos/as sobre como as pessoas transexuais e travestis alteravam as características físicas do seu corpo. Essa situação suscitou inúmeras provocações sobre as diferentes identidades de gênero e como estas identidades são múltiplas e podem ser alteradas. Um dos alunos afirmava que estes sujeitos não seguiam as regras de Deus e mantinham uma conduta inadequada na sociedade. Considerando esta opinião, e assumindo um compromisso com a desconstrução dos preconceitos, realizei uma fala sobre o respeito às diversidades e o direito das pessoas viverem e transitarem em sociedade. Novamente foi argumentado sobre o respeito às diferentes religiões, não existindo verdades absolutas, nem crenças únicas e legítimas, mas que a identidade religiosa não pode interferir na maneira como os outros sujeitos vivem a sua sexualidade e a sua identidade de gênero. (Diário do estagiário - Aula 6).

Essa discussão possibilitou relacionar os conteúdos específicos intrínsecos no conteúdo do sistema genital, com a proposta da educação para a sexualidade, abordando as questões biológicas, considerando o contexto social e os diferentes sujeitos presentes nele. Buscou-se discutir o gênero como um artefato social, cultural e histórico, que engloba os processos que diferenciam mulheres de homens (LOURO, 2010). Nessa perspectiva, diversas instâncias socias e artefatos culturais são "generificados", ou seja, produzem e reproduzem representações de masculinidade e feminilidade; tais representações ao interpelarem os sujeitos produzem identidades e subjetividades.

Nas aulas 7, 8, 9 e 10 buscou-se trabalhar o corpo masculino e feminino com foco no sistema genital. Cabe destacar que o uso da terminologia sistema genital buscava romper com o uso dos termos "aparelho reprodutor" e "sistema reprodutor", termos que pressupõem a compreensão do corpo enquanto uma máquina e que o órgão genital tem

Recebido em: $27 / 01 / 2020$ 
o objetivo de reproduzir, o que está relacionado com a "heteronormatividade"2. Ao analisarmos os diários reflexivos dessas quatro aulas percebemos que a abordagem do sistema genital ficou restrita ao discurso biológico, com foco na anatomia e fisiologia dos corpos, embora o tema da unidade de aprendizagem tenha sido a sexualidade na perspectiva da educação para a sexualidade. Com isso, não queremos dizer que o estudo da anatomia e fisiologia dos corpos não é importante, trata-se de compreender que o próprio discurso biológico também é uma construção social, cultural e histórica, portanto, não é neutro, não é imutável, carrega intencionalidades e institui verdades sobre os corpos, bem como, é o conteúdo considerado legítimo para ser trabalhado na escola, abaixo apresentamos um fragmento de uma das aulas que ilustra esse entendimento:

Com os modelos anatômicos em aula pedi para que todos/as manuseassem o material, discutindo com os colegas sobre quais partem poderiam ser identificadas e se estes/as saberiam informar quais as funções das referidas partes estudadas. A turma, apesar de parecer sem entusiasmo para a aula, se envolveu na realização da atividade, discutindo e relatando no caderno o que era realizado. Logo, foi questionado de forma individual o que cada um/uma havia percebido de diferente, se reconhecia a anatomia dos sistemas e suas funções. Nesse momento muitos equívocos surgiram, mesmo podendo consultar o material para a melhor compreensão. Assim, se optou pela consulta no livro didático para auxiliar no entendimento do que era visualizado. (Diário do estagiário - Aula 8)

Para a abordagem da sexualidade na perspectiva da educação para a sexualidade, foi solicitado que os/as alunos/as descrevessem quais atividades haviam sido realizadas durante o final de semana. Essa atividade objetivava relacionar a sexualidade com as práticas cotidianas, a fim de apresentar um entendimento mais amplo sobre o que é a sexualidade. Conforme argumenta Ribeiro (2008, p. 37) é importante "discutir e refletir sobre a sexualidade em uma outra perspectiva, na qual ela é tomada como produzida nos acontecimentos históricos e culturais das experiências das pessoas, ao correlacionar nos corpos comportamentos, linguagens, representações, crenças, identidades". Desse modo, não podemos simplesmente explicar e compreender a sexualidade na perspectiva biológica, uma vez que a própria biologia adquire sentido socio-histórico. Contrapondonos as abordagens determinista e essencialista da sexualidade, buscamos repensar com os/as alunos os entendimentos atribuídos à sexualidade e às suas práticas, possibilitando outras formas de compreender a sexualidade, sem com isso desconsiderar a materialidade biológica, mas questionar as produções sociais baseadas na natureza biológica dos corpos. Como mostram os fragmentos abaixo:

A aula iniciou com o seguinte questionamento: o que é sexualidade? Uma diversidade de respostas emergiu, mas todas estavam ligadas ao sexo, enquanto relação sexual, prazer, atração, diferentes práticas, posições sexuais, desenvolvimento dos órgãos genitais, estudo do sistema genital e o que diferenciava as pessoas em homens e mulheres. Anotei estas respostas no quadro e, posteriormente, realizei uma fala com um entendimento diferente sobre sexualidade, como a forma das pessoas viverem e experimentarem seus desejos e prazeres. Não apenas desejos e prazeres ligados ao sexo, mas distanciando-se dessa

\footnotetext{
2 De acordo com Santos (2009), "heteronormatividade" é uma palavra fruto da junção de "hetero" (de heterossexual) e "norma", isto é, regras, "coisas" que são assumidas como reguladores importantes que devem ser seguidos sob o desígnio de uma lei ou princípio moral. Portanto, a "heteronormatividade tem a ver com heterossexualidade e com normas, regras, modelos, padrões. Em outras palavras, trata-se de um padrão de sexualidade que tem a qualidade ou força de uma norma" (SANTOS, 2009, p. 25).
} 
compreensão, ampliando para todas as situações que estes/as consideram prazerosas como comer, ouvir música, dançar e tantas outras possibilidades que se pode aproveitar de maneira saudável. Essa provocação desacomodou a maioria que não entendia como essas situações poderiam ser consideradas a "sua sexualidade e a sexualidade dos/as colegas", esse novo entendimento apresentado gera conflito, pois é naturalizado o entendimento de sexualidade preso ao sexo. (Diário do estagiário - Aula 11).

Iniciei a aula pedindo para que eles/elas descrevessem quais foram as principais atividades que realizaram durante o final de semana. Muitas situações emergiram deste questionamento, tais como: jogar vídeo game, ouvir música, passear, festas, reuniões familiares, frequentar a igreja e, principalmente, conectar-se à internet. Com estas respostas retomou-se o conceito de sexualidade apresentado na aula anterior, em que eles/as puderam relacionar o que havia sido trabalho com situações que aconteceram no seu final de semana. Assim, foi possível perceber a sexualidade como algo relacionado ao contexto social e cultural que eles/as estão inseridos/as, sendo que este contexto sofre alterações durante a história, mudando dessa forma, sua sexualidade. (Diário do estagiário - Aula 12).

A aula 15 foi a aula reservada para apresentação dos trabalhos sobre IST organizados no decorrer do período de regência do Estágio Supervisionado II. Para tanto os/as alunos/foram divididos/as em grupos de 4 a 5 componentes que deveriam apresentar uma das infecções sexualmente transmissíveis escolhidas previamente pelo acadêmico-estagiário, tais como: HIV, gonorreia, sífilis, HPV. Os grupos dispunham de um intervalo de tempo que variava entre 5 a 10 minutos e se escolheu utilizar como recurso visual cartazes por serem instrumentos que podem ser construídos com materiais de baixo custo. As apresentações deveriam conter a caracterização das IST, formas de transmissão, principais sintomas, tratamento e métodos de prevenção. Os critérios de avaliação foram o domínio da temática abordada, a organização dos cartazes e o envolvimento dos/das integrantes do grupo durante a apresentação. Se optou pela apresentação oral, na forma de seminário, considerando que a sala de aula, especialmente no Ensino Fundamental, para além de conceitos específicos, se constrói habilidades multidisciplinares. Nesse sentido, nosso argumento encontra embasamento nas palavras de Goulart (2017) ao afirmar que as apresentações orais como seminários em sala de aula se tornam "um espaço de entrecruzamento entre as modalidades falada e escrita e entre os polos prototípicos (oral-escrito), além dos aspectos multissemióticos a gestualidade, os movimentos faciais e corporais, a velocidade da voz, a entoação, o riso - próprios dos gêneros orais" (GOULART, 2017, p. 237). A escrita reflexiva decorrente da aula 15 é trazida a seguir:

Os trabalhos ficaram muito abaixo do esperado, as construções foram pouco elaboradas, e as informações retiradas na íntegra de uma única fonte, estando sempre um ou dois integrantes à frente do trabalho, tomando iniciativa na hora da fala. A alternativa para esta situação poderia ser que uma aula na íntegra tivesse sido dedicada à elaboração deste trabalho com orientações mais claras e objetivas os resultados poderiam ter sido diferentes e mais satisfatórios. (Diário do estagiário - Aula 15)

Uma das atividades relevantes do estágio foi a atividade denominada "Fala sério ou com certeza" (MAGALHÃES, 2013), que teve por objetivos problematizar verdades naturalizadas sobre os diferentes temas estudados (Corpo, Gênero, Sexualidade e Identidade). Como vemos na seguinte reflexão:

Para este momento, planejou-se uma dinâmica intitulada "Fala sério ou com certeza". Essa atividade consistia no sorteio de afirmativas referentes a inúmeros assuntos, tais como: sexualidade, diferenças, diversidades, IST, métodos contraceptivos, gravidez na adolescência, masturbação, entre outros. Cada 
aluno/a ao sortear deveria argumentar se a afirmativa estava correta (com certeza) ou falsa (fala sério). Os meninos cochichavam em pequenos grupos e as meninas faziam perguntas de suas dúvidas. Abordei questões como as crenças e tabus sobre masturbação, a atribuição da masturbação ao sexo masculino, formas de prevenção tanto de gravidez como IST, responsabilidades de homens e mulheres. Foi interessante perceber que as perguntas eram destinadas a ambos os gêneros, porém quando uma pergunta sobre pílula anticoncepcional foi lida por um menino foi motivo para tensão e brincadeiras. (Diário do estagiário - Aula 16)

Essa atividade possibilitou revisar conteúdos trabalhados que foram trabalhados, bem como problematizar mitos e tabus que cercam a sexualidade, reafirmando os argumentos construídos nas aulas anteriores, de maneira prática e dinâmica através do diálogo. A abordagem com que a aula foi conduzida permitiu que o diálogo predominasse no decorrer da realização da atividade, o que permitiu uma interação muito maior entre os/as alunos/e destes/com o acadêmico-estagiário. Quando decidimos desenvolver um trabalho fundamentado na perspectiva da Educação para a Sexualidade, não podíamos organizar aulas tradicionais e condicionar os/as alunos/alunas transmissão passiva do conhecimento, visto que isso contraria a própria intenção de questionarmos a normativas que compõem os sistemas de produção de conhecimento. Assim, assumimos a dialogia estabelecida a partir das práticas dialógicas como um modo de tornar o processo de ensino-aprendizagem efetivo, do ponto de vista da produção de saberes, para os/as alunos/alunas e acadêmico-estagiário.

Os relatos apresentados compreendem de forma parcial o trabalho desenvolvido no decorrer de estágio supervisionado II, mas que evidenciam a possibilidade de trabalhar na perspectiva da educação para a sexualidade conforme aponta Xavier Filha (2009) a partir do desenvolvimento de unidades de aprendizagem a fim de superar a fragmentação curricular, abordando conteúdos que se articulem às necessidades, vivências e realidades dos/as alunos/as. A seguir tecemos algumas considerações finais acerca do desenvolvimento do trabalho.

\section{4. (IN)CONCLUSÕES}

A partir do exposto, considera-se que o desenvolvimento do estágio supervisionado II na perspectiva da educação para a sexualidade possibilitou uma ampliação dos entendimentos referentes ao tema, desconstruindo discursos e práticas naturalizadas pela sociedade. Realizar as atividades, assumindo a educação para a sexualidade como fundamento das ações educativas, contribui para a ruptura e superação de preconceitos, o que possibilita a formação de sujeitos socialmente responsáveis, colaborando para a construção de uma sociedade mais justa e igualitária. Porém, estas práticas foram realizadas durante as aulas de Ciências, o que reforça a compreensão de que sexualidade está ligada ao discurso biológico, e que somente os/as professores/as que trabalham com esta área do conhecimento podem dispor do seu tempo e espaço para se abrir estas discussões. O que entendemos é que os/as professores/as de diferentes áreas do conhecimento devem ser capazes de abordar e desenvolver práticas pedagógicas na perspectiva da educação para a sexualidade, contribuindo para a construção de uma escola múltipla, inclusiva e democrática. 
Para tanto, consideramos importante a inserção de temas como corpo, gênero e sexualidade nos currículos dos cursos de licenciatura, a fim de formar profissionais preparados/as para trabalhar na perspectiva da diversidade e da garantia dos direitos humanos.

O desenvolvimento do estágio supervisionado II configurou-se como espaço e tempo de formação profissional docente, possibilitando a articulação entre teoria e prática através da inserção do estagiário na realidade da escola pública. A partir desta experiência de estágio, foi possível perceber determinados pontos que podem ser melhorados e repensados, tais como a abordagem exclusiva do discurso biológico, sem a preocupação de discutir com a turma como esse discurso foi produzido ao longo dos séculos. Ao revisitarmos o estágio supervisionado II através dos diários reflexivos do estagiário percebemos como essa experiência foi produtiva, possibilitando a investigação do ambiente escolar, a partir da ação-reflexão das práticas desenvolvidas. Além disso, percebemos que a proposta suscitou diversos efeitos na turma de estágio, tais como a desestabilização dos entendimentos sobre a sexualidade e os corpos, a possibilidade de pensar de modo plural e a necessidade de respeitar as diferenças no exercício da alteridade.

Ao realizar o estágio supervisionado II na perspectiva da educação para a sexualidade assumimos um compromisso social com a intenção de constituir a partir do diálogo, da problematização e da desconstrução de discursos naturalizados caminhos possíveis para a compreensão e vivência da sexualidade livre de tabus e preconceitos.

\section{REFERÊNCIAS}

BRASIL. Secretaria de Educação Fundamental. Parâmetros curriculares nacionais: ciências naturais /Secretaria de Educação Fundamental. Brasília: MEC/SEF, 1997.

BRASIL. Lei 11.788, de 25 de setembro de 2008. Dispõe sobre os estágios de estudantes (e outras disposições...). Disponível em:

http://www.planalto.gov.br/ccivil_03/_ato2007-2010/2008/lei/111788.htm. Acesso em: set. de 2019.

CANDAU, Vera Maria. Multiculturalismo e educação: desafios para a prática pedagógica. In: MOREIRA, Antonio Flávio; CANDAU, Vera Maria (orgs.).

Multiculturalismo: diferenças culturais e práticas pedagógicas. 10. ed. Petrópolis, RJ: Vozes, 2013. P. 13-37.

DOLESKI, Lisiane Ribeiro; SILVA, Fabiane Ferreira da. Diários de uma professora estagiária: problematizando o saber da experiência nos estágios supervisionados em Ciências da Natureza. Travessias, Cascavel, v. 13, n. 2, p. 193-214, maio/ago. 2019. Disponível em: http://e-

revista.unioeste.br/index.php/travessias/article/view/22553/14613. Acesso em: 14 dez. 2019. 
FREIRE, Paulo. Pedagogia da autonomia: saberes necessários à prática educativa. 25. ed. São Paulo: Paz e Terra, 1996.

GALIAZZI, Maria do Carmo; GARCIA, Fabianne Ávila; LINDEMANN, Renata Hernandez. Construindo Caleidoscópios: organizando unidades de aprendizagem. In: MORAES, Roque; MANCUSO, Ronaldo. Educação em Ciências: produção de currículos e formação de professores. Ijuí: Editora da UNIJUÍ, 2004. P. 65-84.

GOULART, Cláudia. A caracterização do gênero exposição oral no contexto das práticas de linguagem na escola. Olhares \& Trilhas, Uberlândia, v. 19, n. 2, jul./dez. 2017. Disponível em:

http://www.seer.ufu.br/index.php/olharesetrilhas/article/download/40811/21546/. Acesso em: 28 nov. 2019.

HAMES, Clarinês; KEMP, Adriana Toso. Diversidade de Gênero e Sexualidade no Processo Formativo Docente, Revista Insignare Scientia, v. 2, n. 1, p. 67-74, Jan./Abr. 2019. Disponível em:

https://periodicos.uffs.edu.br/index.php/RIS/article/view/10664/7142. Acesso em: 6 mar. 2020.

KRASILCHIK, Myriam. Prática de Ensino de Biologia. 4. ed. São Paulo: Editora da Universidade de São Paulo, 2008.

LOURO, Guacira Lopes. Sexualidade: lições da escola. In: MEYER, Dagmar E. (Org.). Saúde e Sexualidade na Escola. 2. ed. Porto Alegre: Mediação, 2000. P. 85-96.

LOURO, Guacira Lopes. Gênero, sexualidade e educação: Uma perspectiva pósestruturalista. Rio de Janeiro: Vozes, 2010.

MAGALHÃES, Joanalira Corpes. Fala sério ou com certeza? In: RIBEIRO, Paula. Regina. Costa. QUADRADO, Raquel. Pereira (Org). Corpos, gêneros e sexualidades: questões possíveis para o currículo escolar. Caderno Pedagógico, Anos Finais. 2 ed. Rio Grande: Editora da FURG, 2013. P. 82-84.

PIMENTA, Selma Garrido; LIMA, Maria Socorro Lucena. Estágio e Docência. São Paulo: Cortez, 2004.

PINTO, Neusa Bertoni. Contrato didático ou contrato pedagógico? Revista Diálogo Educacional, Curitiba, v. 4, n.10, p.93-106, set./dez. 2003. Disponível em: https://periodicos.pucpr.br/index.php/dialogoeducacional/article/view/6437. Acesso em: 25 nov. 2019

QUADRADO, Raquel Pereira. Muito além do orgânico: corpos hibridizados pela tecnologia. In: RIBEIRO, Paula Regina Costa; SILVA, Fabiane Ferreira da; MAGALHÃES, Joanalira Corpes; QUADRADO, Raquel Pereira. Educação e sexualidade: identidades, famílias, diversidade sexual, prazeres, desejos, preconceitos, homofobia... Rio Grande: Editora da FURG, 2008. P. 45-50. 
QUADRADO, Raquel Pereira. Práticas bioascéticas contemporâneas: notas sobre a produção dos corpos nas diversas instâncias sociais. In: SILVA, Fabiane Ferreira da; FREITAS, Diana Paula Salomão de (Orgs.). II Seminário Corpos, Gêneros, Sexualidades e Relações Étnico-Raciais na Educação [recurso eletrônico]. Uruguaiana, RS: UNIPAMPA, 2012. P. 10-25. Disponível em: https://sites.unipampa.edu.br/sisbi/files/2013/07/corpos-2012.pdf. Acesso em: 27 jan. 2020.

RIBEIRO, Paula Regina Costa. Inscrevendo a sexualidade: discursos e práticas de professoras das séries iniciais do Ensino Fundamental. 2002. 125f. Tese Doutorado em Ciências Biológicas (Bioquímica), Instituto de Ciências Básicas da Saúde, Universidade Federal do Rio Grande do Sul, Porto Alegre.

RIBEIRO, Paula Regina Costa. A sexualidade e o discurso biológico. In: RIBEIRO, Paula Regina Costa; QUADRADO, Raquel Pereira. Corpos, gêneros e sexualidades: questões possíveis para o currículo escolar. Caderno Pedagógico, Anos Finais. 2. ed. Revisada e ampliada. Rio Grande: FURG, 2008. P. 35-38.

SANTOS, Luis Henrique Sacchi dos. Heteronormatividade \& educação. In: PENALVO, Cláudia; BERNARDES, Gustavo. (Org.). Tá difícil falar sobre sexualidade na escola? Porto Alegre, 2009. P. 26-36.

SILVA, Fabiane Ferreira da. Linguagens, estilos, adornos corporais...: a produção das identidades adolescentes na contemporaneidade. In: RIBEIRO, Paula Regina Costa; SILVA, Fabiane Ferreira da; MAGALHÃES, Joanalira Corpes; QUADRADO, Raquel Pereira. Educação e sexualidade: identidades, famílias, diversidade sexual, prazeres, desejos, preconceitos, homofobia... Rio Grande: Editora da FURG, 2008. P. 89-95.

SILVA, Fabiane Ferreira da. Lições de sexualidade na escola. In: SILVA, Fabiane Ferreira da; MELLO, Elena Maria Billig (Org.). Corpos, gêneros, sexualidades e relações étnico-raciais na educação [recurso eletrônico]. Uruguaiana, RS: UNIPAMPA, 2011. P. 146-157. Disponível em: http://porteiras.r.unipampa.edu.br/portais/sisbi/. Acesso em: 27 jan. 2020.

UNIPAMPA. Universidade Federal do Pampa / Ciências da Natureza. Projeto Pedagógico do Curso de Ciências da Natureza, Uruguaiana, 2013. Disponível em: http://cursos.unipampa.edu.br/cursos/cienciasdanatureza/files/2011/05/PPCCi\%C3\%AAncias-Natureza.pdf. Acesso em: 18 out. 2019.

XAVIER FILHA, Constantina. Educação para a sexualidade: carregar água na peneira? In: RIBEIRO, Paula Regina Costa; SILVA, Méri Rosane; GOELLNER, Silvana Vilodre (Org.) Corpo, gênero e sexualidade: composições e desafios para a formação docente. Rio Grande: FURG, 2009. P. 85-103. 
ZABALZA, Miguel A. Diários de aula: um instrumento de pesquisa e desenvolvimento profissional. Porto Alegre: Artmed, 2004. 